\title{
MISCELÁNEA
}

\section{ORIGEN DEL PARTICIPIO PASADO CON COMPLEMENTO DIRECTO}

\author{
F. González Ollé.
} Universidad de Navarra.

1. Entre las lenguas románicas (al menos en las de larga tradición y sólida coherencia), el participio pasado con complemento directo únicamente se documenta de modo concluyente en español, donde no se había observado en cuanto tal hasta hace escaso tiempo ${ }^{1}, \mathrm{y}$, con mayor rotundidad, en italiano. Entre ambas lenguas se observan, referidas a la cuestión presente, notables diferencias sintácticas, cuya exposición no es ahora del caso. Pero sí ha de consignarse que mientras en español moderno esa relación, pese a su anterior arraigo y variada tipología, se encuentra muy debilitada, respecto al italiano esa misma función, manifestada mediante la enclisis pronominal en dicha forma infinita, ha sido favorecida por el uso corriente a lo largo de toda su historia. Se comprende, por tanto, que haya constituido objeto de estudio desde tiempo atrás y que, en consecuencia, una gramática monumental como la de Renzi ${ }^{2}$ pueda limitarse a aseverar sobre este punto: "Con verbi al modo infinito, il clitico segue il verbo: Vistolo, fu facile catturarlo", al igual que lo dictamina, con más detalle, otra tanibién reciente ${ }^{3}$ : las formas átonas de los pronombres personales "diventano enclitiche $[\ldots]$ con un participio passato usato in forma assoluta o con funzione aggetivale: Salutatolo, si allontand.-La merce consegnatami è avariata. Raro el tipo doppio (al più usato assolutamente): Dettoglielo.-Andarsene".

1 F. González Ollé, "Participio pasado con complemento directo", en Actas del III Congreso Internacional de Historia de la Lengua Española (Salamanca, 1993), en prensa, que aporta 61 testimonios para esta construcción (de ellos, 50 con nombre y 11 con pronombre), muy desigualmente distribuidos respecto a su cronología: a partir del siglo xIII en frecuencia de aparición creciente hasta el xvI, y, desde entonces, decreciente, con sólo cuatro testimonios en el siglo $\mathbf{x x}$.

2 L. Renzi y otros, Grande grammatica italiana di consultasione, Bolonia, 199132, I, pág. 552 .

3 M. Dardano y P. Trifone, Grammatica italiana, Bolonia, 1992, pág. 263. 
Sobre sus caracteristicas existe una antigua y extensa monografia de Skerlj ${ }^{4}$. Según este autor, el participio con complemento directo está ya difundido en italiano durante el siglo xin, circunstancia por la cual no acepta que se explique (como hasta entonces se habia procedido) mediante la omisión de avendo, pues el gerunclio compuesto es más tardio (no se desarrolla hasta el siglo xiv), originado por analogia con las formas perifrásticas finitas: faccio: ho fatto, faccia: abia fatto, etc., dan lugar a avendo fatto.

Para Skerlj, procede de un uso impersonal de sentido activo, a partir de las formas latinas audito, cognito, etc., en ablativo singular neutro, seguidas de una proposición de infinitivo o declarativa con ut o quod. En estas construcciones encuentra "la capacità che tali participi assoluti latini, in quanto appartengono a verbi transitivi, hanno di reggere un complemento diretto". A mi parecer esta explicación resulta inadecuada, puesto que dichas completivas constituyen el sujeto, no el objeto del participio. Skerlj supone también que el latín tardio experimentó la tendencia a crear un participio perfecto activo, que faltaba en latín clásico (y que tienen, por ejemplo, las lenguas eslavas). El germen de la innovación se encontraría en los casos en que los dos elementos del ablativo absoluto están separados por el sujeto de la oración principal (ejemplos de esta secuencia, en § 7).

Destacados lingüistas posteriores aceptan la explicación (elipsis de avendo) rechazada por Skerlj. Rohlfs ${ }^{5}$ afirma, a mi entender con poca precisión en su planteamiento, que "il participio dei verbi transitivi anticamente poteva anche non concordare col nome". Cita testimonios de Boccaccio: Vedutola e bella parendogli.-Maquiavelo: Il cavaliere, veduto la belleza della fanciulla, si accese. Etc. "Anche il participio dei verbi intransitivi poteva restare invariato", como en este pasaje, entre otros, de Ariosto: Morto i fratelli $e$ il padre. Ante tales usos, descarta claramente la procedencia del ablativo absoluto latino, portador de "un' idea verbale passiva" y proclama que la construcción italiana "proviene dall'abbreviamento d'un gerundio passato: (avendo) finito la lettera".

También Tekavcic ${ }^{6}$ sostiene que la elipsis del gerundio compuesto origina la secuencia (avendo) venduto la casa, ya que dicho tiempo debió de haberse formado pronto por analogía de los compuestos finitos, pese a s11 relativamente tardía aparición.

Wanner ${ }^{7}$, practicante de una metodología generativista, también admite

4 S. Skerlj, "Construtti participiali del tipo «veduto la belleza»", L'Italia dialettale, 1932, 8, págs. 117-78. Conozco este artículo sólo a través de su eco en la bibliografía posterior.

5 G. Rohlfs, Grammatica storica della lingwa italiana e dei suoi dialetti, Turín, 1969, III, pág. 118.

B P. Tekavcic, Grammatica storica dellitaliano, Bolonia, 1972, II, págs. 544-6.

7 D. Wanner, The Development of Romance Clitic Pronouns. From Latin to Ro- 
ser alineado entre quienes participan de la creencia en la elipsis de avendo, a juzgar por estas palabras: "An absolute ppl [past participle] has the semantic force of a corresponding expression with ger (aux) $+p p l$ as a past gerund (visto il fatto $=$ avendo visto il fatto) in all the absolute gerundial functions compatible with an anterior time frame."

Aunque ampliamente atestiguado en época medieval ${ }^{8}$, el participio con complemento directo parece haber sido considerado por Migliorini ${ }^{9}$ como construcción característica del siglo XVI, a juzgar por la más precisa atención que le dedica al estudiar la sintaxis de esta época respecto a otras: "En las construcciones participiales absolutas, el participio frecuentemente queda en masculino singular." Aduce casos como: Fatto Pasqua (Bembo).-Stracciato la scritta (Grazziani).-Restato la femmina contenta (Doni). Etc.

2. Hasta donde me ha sido posible examinarlas, la tradición gramatical española y la italiana se han ignorado mutuamente $\mathrm{y}$, por supuesto, cada una (salvo la puntual observación de Cuervo ${ }^{10}$, carente de repercusiones) desconoce el comportamiento de la lengua ajena. Las razones de esta situación - diversas en cada lado- son fáciles de descubrir y no merece la pena detenerse en ellas. Pero sí importa destacar esa misma situación, porque el haberse desenvuelto con independencia confiere especial fuerza al hecho de que, a la hora de presentar una explicación, ambas recurran al mismo argumento: la elipsis del gerundio auxiliar del participio ${ }^{11}$.

Personalmente, el socorrido recurso a la elipsis no acaba de convencerme para este caso concreto. Una cosa es que el participio admita en casi todos los testimonios de la naturaleza examinada (juzgo de los españoles) ser conmutado por el gerundio compuesto sin alteración funcional alguna, y otra que en los testimonios conocidos se haya producido de hecho la elipsis. En mi opinión, el desconcierto suscitado ante la existencia de una forma históricamente pasiva por su origen que se presenta con complemento directo, obliga a una explicación; ésta se ha obtenido, de manera cómoda, por el recurso citado.

3. Sin constituir razón de suficiente peso para oponerse a la sostenida elipsis de habiendo, no puedo pasar por alto, pese a su proporcionalmente

mance, Berlín, 1987, pág. 265. No se ocupa del participio en su artículo "The Order of Clitics in Italian", Lingua, 1977, 43, págs. 101-28.

8 Extensa documentación en F. Brambilla Ageno, $I l$ verbo nellitaliano antico. Ricerche di sintassi, Milán, 1964, págs. 164-7, donde establece una variada tipología.

- B. Migliorini, Historia de la lengua italiana, Madrid, 1969, I, pág. 543.

10 F. González Ollé, "Participio pasado ...", \& 6.

11 Ib., §§ 9-11 y, aquf, \& 1 . Desde otra perspectiva metodológica, cf. los estudios citados en la nota 28 del presente. 
escasa incidencia el dato de que no todos los testimonios admiten dicha causa, es decir, no cabe en ellos la conmutación. Detallo estas varias excepciones encontradas en la nómina de mi precedente estudio:

No quería admitir Ministro en su corte ni yo dádole respuesta (B. Mendoza, Carta) exige, sin necesidad de explicitarlo, el precedente quería (verbo con el que aparentemente va coordinado el participio) y la conversión de éste en infinitivo: (quería) darle respuesta.

Yo querría que fuéssedes a ver la playa de Marbella y meneado alli las plumas de las gurapas (A. de Salazar, Response) exige querria, en las mismas condiciones que el ejemplo anterior, pero no infinitivo, pues cambia el sujeto, sino verbo auxiliar en forma personal: (querría) que hubiéssedes meneado las plumas.

Aquella roca se habia de rendir poco a poco, pues lo más estaba hecho, que era echar a un lado la santimoña y quitándose la máscara (A. Castillo Solórzano, La Garduña de Sevilla).-Después de acostado Su Excelencia y dado nuevas materias para el día siguiente, era necesario recorrer las murallas (D. Duque de Estrada, Comentarios del desengañado de si mismo).Fue convencido en sesión secreta $[\ldots]$ de ser un gran bribón $y$ hecho las más odiosas bajezas en el Gobierno (P. A. Girón, Recuerdos). En estos tres textos, sus respectivos participios, quitado, dado y hecho, exigen por igual el infinitivo haber.

Yo estuve en la Secretaría de Estado todo el tiempo que duró el conflicto, $y$ después de terminado, $y$ visto al Señor Presidente [...], me volví (P. A. Girón, Recuerdos).-Después de preguntarse cómo habian pasado la noche $y$ respondídose cortésmente (F. Santos, Dia y noche de Madrid). En estos dos textos, sus respectivos participios, visto y respondidose, si no rechazan necesariamente el gerundio, se adecuan más al infinitivo haber.

Le expliqué el plan de mi campaña y aun leídole algunas cuartillas (L. Astrana Marin, Profanaciones). El participio exige su transformación en un tiempo personal y perfecto.

Adviértase para todos los precedentes testimonios analizados que la diversa exigencia reclamada respecto a cada uno de ellos ha de entenderse únicamente en cuanto a reformular las oraciones sustentadas por los participios con enclisis pronominal bajo una distinta estructura sintáctica que la conferida por ellos. La finalidad perseguida mediante las transformaciones efectuadas no es otra sino la de mostrar su equiparación con aquellas formulaciones que, por razones meramente estadísticas, cabe estimar las normales y, en consecuencia, suponer que proceden o se han desviado de ellas. El resultado obtenido es ratificar que, por el contrario, no permiten la afirmación de que se hayan originado a partir de la elipsis de habiendo.

De cualquier modo, según anticipé, los diferentes casos en contra de la 
elipsis de habiendo recién examinados no constituirían motivo determinante para oponerse a ella como actitud general, si a su favor esa teoria contase con pruebas de suficiente solidez (recuérdense las objeciones de Skerlj) para atribuirla a los demás. Bastaría entonces, sencillamente, admitir que el participio con complemento directo habia adquirido necesario desarrollo como para implantarse en otros contextos, si respecto a estos últimos no se encontrase alguna otra motivación o motivaciones especificas.

Es cuestión distinta, obviamente, una vez atestiguada la insatisfactoria -aquí, al menos, en cuanto parcial- solución aportada por la elipsis, averiguar qué proceso ha podido experimentar el participio pasivo para alcanzar su nueva capacidad funcional. De ello me ocupo a continuación.

4. Al buscar los orígenes del participio pasivo con complemento directo habrá que volverse, obvio es decirlo, hacia el latín. Con mayor motivo si se ha producido, como en este caso, la coincidencia de dos lenguas románicas respecto de tal fenómeno sintáctico y, además, éste se documenta tempranamente en ellas.

Pues bien, desde principios del siglo actual, por lo menos, ha sido estudiada "die Konstruktion der Ablativi Absoluti mit dem Partic. Perfecti von Deponentien und Semideponentien in Verbindung mit einem Objekte im Akkusative (also mit transitiver Bedeutung)", según la descripción de Kühner ${ }^{12}$. El testimonio de mayor antigüedad mencionado por él: Sulla omnia pollicito, pertenece a Salustio (86-35 a. C.), dato que se sigue repitiendo hasta el presente en los más conocidos tratados de sintaxis latina. El citado tipo de ablativo absoluto es una construcción no clásica, de escasa aparición, comenta el propio Kühner, que aduce también el testimonio de Tito Livio (59 a. C. -17 d. C.): Hasdrubale auso facinus. Para Hofmann ${ }^{13}$ se propaga desde los verbos deponentes, como en el ejemplo de Salustio, hasta los semideponentes, que atestigua Tito Livio. Bassols ${ }^{14}$ apunta una nueva extensión: "En el latín decadente también los participios perfectos de verbos activos (y que, por tanto, deberían tener acepción pasiva) admiten a veces esta construcción: perpetrato facinus, amnem congelato (Iordanes [siglo vi])." Testimonios del latín tardio, anteriores a los últimamente citados,

18 R. Kühner - C. Stegman, Ausführlich Grammatik der lateinischen Sprache [1912], Hannover, 1971, II, 1, pág. 783.

1s J. B. Hofmann y A. Szantyr, Lateinische Syntax und Stilistik, Munich, 1972, pág. 139.

is M. Bassols, Sintaxis latina, Madrid, 1971, I, pág. 153. Los ejemplos que aduce habían ya sido presentados por E. Löfstedt, Philologischer Kommentar sur Peregrinatio Aetheriae, Upsala, 1911, pág. 292. Por incongruencia entre 'helar', transitivo, según declara, y 'río', me resulta imposible admitir el segundo de los testimonios transcritos arriba. 
presenta asimismo Hofmann ${ }^{15}$ : Nihil impetrato (Ammiano, fines del siglo Iv), con la particularidad, según él, de que el tipo con objeto nominal se desarrolla después: Servato propositum (San Ambrosio, siglo Iv). Copio de Löfstedt ${ }^{16}$ dos más porque en ellos se observa muy bien la falta de concordancia: Completo matutinas, albescente die procedunt (Antonino, Itinerarium, fines del siglo II).-Excluso omnia beneficia (papiro, h. 570).

El enlace cronológico de la documentación bajolatina con los textos primitivos italianos puede observarse a través del copioso repertorio de Brambilla antes citado $(\S 1)$.

5. En atención a su origen hispánico, me decido a traer el siguiente pasaje: Sic fit orationem, de la Peregrinatio Aetheriae. En él, un verbo semideponente pasivo con complemento directo constituye, según la interpretación de Löfstedt ${ }^{17}$, que comparto, una oración impersonal activa. El comportamiento sintáctico de la forma finita autoriza a suponer - entiendo yoigual virtualidad para el participio, es decir, la posibilidad de actuar una construcción como *facto orationem 'habiendo hecho oración'.

Por la misma razón que en el caso anterior, valga presentar, de muchos siglos después, este otro posible testimonio: Excepto ius ecclesie, en un documento de Alfonso VIII (Atienza, 1172), al que Pérez González ${ }^{18}$ atribuye función de ablativo absoluto, aun sin aparecer la forma canónica iure, en virtud de que ius "su sujeto puede considerarse indeclinable". No descarto con rotundidad la validez de su hipótesis. Sin embargo, no sólo por los precedentes expuestos, sino por la posterior evolución sintáctica del participio, me inclino a identificar ius como verdadero acusativo y complemento directo.

6. Mostré antes $(\S 1) \mathrm{mi}$ disconformidad con una de las propuestas de Skerlj : la de considerar complemento directo del participio a determinadas oraciones completivas. Debo declarar ahora, al margen de su posible interés románico, que esta doctrina se viene repitiendo en las gramáticas latinas (desde luego en todas las citadas aqui, que estimo muy representativas). Hace más de un siglo enunciaba ya el conocidísimo manual de Riemann ${ }^{19}$, que "on rencontre quelquefois à l'ablatif absolu un participe passé ayant pour object toute une proposition subordonnée”. Aporta ejemplos de Cicerón, Salustio, etc., y añade que "ce tour est fréquent chez $\mathrm{T}$. Live et à l'époque impériale, mais fort rare dans l'ancienne langue". Acepto, o mejor, acato,

\footnotetext{
15 J. B. Hofmann, Lateinische ..., pág. 142.

16 E. Löfstedt, Philologischer ..., pág. 292.

17 Ib.

18 M. Pérez González, El latín de la Cancillería castellana (1158-1214), Salamanca, 1985, pág. 140.

10 O. Riemann y A. Ernout, Syntaxe latine [1886], París, 19427, pág. 533.
} 
esta creencia común entre los latinistas, pero no comprendo cómo se puede sostener ese análisis; en especial ante determinadas secuencias, tal la siguiente, expresamente aducida por Hofmann ${ }^{20}$ al efecto: Impetrato prius a consulibus ut ... permitterent (Q. Claudius Quadrigarius [siglo I a. C.]), puesto que la presencia del sujeto agente, en ablativo, impide la adscripción activa.

7. En su detenido examen del ablativo absoluto latino, Kühner ${ }^{21}$ observa que, a menudo, en César, Tito Livio, Tácito y otros autores, el sujeto de la oración principal se coloca entre los constituyentes de aquella construcción, produciendo la apariencia de que el participio se aplica también a dicho sujeto: Hac re statim Caesar per speculatores cognita... exercitum castris continuit. Con mayor facilidad se provocará esa falsa apreciación si existe concordancia de género y número entre el sujeto y el participio, como ocurre en: Recepto Caesar Orico nulla interposita mora Apolloniam proficiscitur (César, Civ., III, XII, 1).

Estimo que esta disposición táctica ha podido jugar un papel importante para la constitución del participio con complemento directo ${ }^{22}$. Al sentirse sicológicamente el sujeto de la oración principal como sujeto de la forma verbal infinita, dada su proximidad sintagmática, el verdadero sujeto (pasivo) del participio pasa a sentirse como complemento directo y puede acabar adoptando la marca flexiva propia de éste, es decir convertirse en un auténtico acusativo morfológico. Para comprender el proceso descrito resulta de gran utilidad, a mi juicio, analizar la causa del error en que incurre Rodríguez Marín a propósito de una frase española así dispuesta: Oido esto Rosardo, con menos colores en el rostro, no pudo negar (A. Castillo Solórzano, Huerta de Valencia), que en vano trata de justificar sintácticamente. El remedio necesario y suficiente consistía, después de haber puntuado con propiedad, en leer: Oido esto, Rosardo ... no pudo negar, para reducir sin más complicaciones la falsa anomalía. Cierto que Rosardo no es el sujeto gramatical de oído, pero a él afecta el acto de oír y, tras tomarse acertadamente como su sujeto real, llega a considerarse sujeto gramatical. La contigüidad lineal, ayudada por la ausencia de coma (pausa) a continuación del ablativo absoluto (oido esto), puede provocar una equivocada interpretación, como en efecto sucedió a Rodríguez Marín.

8. Aunque los latinistas discrepen en cuanto a su origen, el acusativo absoluto se documenta desde la primera mitad del siglo inr d. C. y a partir

20 J. B. Hofmann, Lateinische ..., pág. 141.

21 R. Kühner, Ausführliche ..., II, 1, pág. 783.

22 Parece que Skerlj (\$ 1) - no puedo asegurarlo, pues, como advertí, sólo indirectamente he podido conocer su artículo- aludió a esta causa. De ser así, me extraf́a mucho que sus continuadores no la tomen en cuenta y que se queden en reafirmar, contra él, el efecto ejercido por la elipsis de avendo. 
de este momento su frecuencia se incrementa de modo considerable ${ }^{23}$. Según Bonnet ${ }^{24}$, se encuentran casi 200 ejemplos de ese giro sintáctico en los seis primeros libros de la Historia Francorum, de San Gregorio de Tours (siglo vi). Con él rivaliza el ya mencionado Jordanes respecto a incidencia de uso; en otros autores se muestra poco extendido.

El acusativo se alinea, pues, junto al ablativo en proporción demasiado amplia para interpretarlo como resultado de confusiones accidentales. Es decir, concluye Bonnet, San Gregorio considera tan legítimo el acusativo absoluto como el ablativo absoluto. Por mi parte, destaco el siguiente testimonio entre los que aduce Bonnet: Auditas Godigisilus Clodouechi uicturias misit ad eum legationem, en cuanto que el acusativo absoluto responde a la misma ordenación táctica que el antes mencionado ( $(7)$ ablativo absoluto de César, cuyo interés para la génesis del participio con complemento directo me permito encarecer.

Documenta también Bonnet ${ }^{25}$ que, a menudo, ambas construcciones absolutas, la de ablativo y la de acusativo, están presentes en proposiciones "étroitemente liées", como se observa, al igual que en otros muchos, en los siguientes pasajes: Obtenta uicturia promissam Clodouecho aliquam partem regni sui cum pace discessit.-Acceptam a nobis benedictionem purgatoque pectore.

Conocida esta situación, pienso que la coexistencia de ablativo y acusativo absolutos podría acabar provocando el cruce de los dos giros y llegarse a un tercero, con el participio en ablativo y el sustantivo en acusativo, bien como sujeto o, sobre todo, como complemento directo. La posibilidad, por tal vía, de forjarse, más exactamente, de recrearse esta última variedad (como quizá ocurre al testimonio español citado en $\S 5$ ) es lo que aquí interesa atender. Para su constitución ha de contarse con que también pueden contribuir a ella las interferencias experimentadas por el paradigma flexivo, es decir, la generalización creciente del acusativo como único caso oblicuo en detrimento de los demás.

23 No faltan, sin embargo, indicios de que esta construcción se sintió como anómala. Según ha probado I. García Arribas, "Acusativo y nominativo absolutos en la Mulomedicina y en Vegecio", CFC, 1977, 13, págs 201-6, los numerosos casos registrados en aquel texto (mediados del siglo IV) son sometidos a corrección por Vegecio (finales del mismo siglo), que los omite o sustituye el acusativo por otra formulación sintáctica, con un claro propósito de regularización. Adviértase que García Arribas, para quien la aparición del acusativo absoluto está provocada por la decadencia casual, considera representativa la actitud de Vegecio en cuanto a marcar una interrupción de ese proceso de desvanecimiento morfológico en el periodo comprendido entre la Mulomedicina y autores como Eteria y San Gregorio de Tours, pródigos en el empleo del acusativo absoluto.

* M. Bonnet, Le latin de Grégoire de Towrs, París, 1890, pág. 561.

25 Ib., pág. 562. 
No he visto formulada esta hipótesis en la bibliografía que vengo citando ni en alguna otra consultada sobre el tema, pero es que apenas merecía prestarle particular atención, salvo a quienes estuvieran interesados por investigar la materia aquí examinada ${ }^{26}$.

La exposición recién desarrollada lleva a afirmar con fundamento que el acusativo absoluto (sin desconocer que para muchos latinistas procede del ablativo) hubo de favorecer en época latina tardía (la de su auge) la construcción de participio en ablativo con un nombre en acusativo.

9. Se impone un balance de la indagación retrospectiva hasta ahora verificada. Cabe asegurar - éste es el logro más importante de los alcanzadosque el participio pasivo con complemento directo está bien atestiguado en latin desde época temprana, aunque dicha construcción diste mucho de constituir una secuencia habitual.

Bastan los pocos testimonios aquí seleccionados para mostrar su continuidad durante siete siglos ( 1 a. C. a vi d. C., §§ 4-5). Obviamente, podría trazarse -y deberá trazarse- esa historia con más documentación y detalle, para ver cómo diversas causas (contaminación verbal, orden de palabras, acusativo absoluto, cruces sintagmáticos) actuaban a favor de que se incrementase la frecuencia del tipo sintáctico examinado. Pero los datos reunidos resultan suficientes con holgura para señalar que el participio pasivo románico con complemento directo cuenta con el antecedente histórico del latín.

10. Cabria, pues, sin más, concluirse que la construcción románica responde fundamentalmente, de modo primario, a una natural continuación de la latina, sin necesidad de recurrir a la ya criticada explicación (§§ 1-3) sostenida en la elipsis del verbo auxiliar bajo su forma de gerundio. Pero, tampoco, sin rechazar de plano la posible cooperación de ésta a la pervivencia de aquélla. La escasa, hoy por hoy, documentación medieval española proyecta alguna incertidumbre sobre el aserto inicial en cuanto a su aplicación a esta área. Bien es verdad, por contra, que la mayor antigüedad y duración

\footnotetext{
26 A la excelente información y amabilidad del Prof. Narbona Jiménez debo el conocimiento, a última hora, de la monografía de A. Helttula, Studies on the Latin Accusative Absolute, Helsinki, 1981. En cuanto se me alcanza, la considero, al menos, una equilibrada síntesis del tema, basada principalmente en documentación ya exhumada. Para el objeto presente contiene algunos datos de interés, como las que denomina mixed constructions, entendiendo por tales aquellas en que falta la concordancia casual en la combinación de participio y sustantivo: si uno de ellos se presenta en acusativo, el otro aparece en ablativo; incluso en enunciados con dos sustantivos, éstos pueden diferenciarse morfológicamente. Reproduzco unos pocos testimonios: Rex permisit ewam abire, retentum secum infantwlo.-Subcriptis ea quae locuti fuerant.-Adprehensis Platonem archidiaconum et Galienum.-Convocatis monachis et matrem (ejemplos todos extraidos de San Gregorio de Tours).
} 
de los equivalentes testimonios italianos, al asegurar la hipótesis de la persistencia ininterrumpida del participio con complemento directo, aportan una información que, sin extrapolarla, tampoco debe desconocerse cuando se estudia, fuera del ámbito italiano, la presencia del participio pasivo con complemento directo.

Me inclino, en consecuencia, a postular la solución de continuidad histórica para el español, sin descartar que, junto a las causas secundarias ya mencionadas $(\S 9)$, y con más alcance que ellas, una nueva influencia pudiera haber contribuido a su fortalecimiento. Pienso en un proceso de contaminación o analogía.

Con el fin de poder valorar mejor el alcance operativo de este recurso, quiero recordar, antes de mostrar su posible influencia en el caso presente, otro fenómeno sintáctico, por completo ajeno al aquí analizado, para el que se ha propuesto similar solución formal. Al preguntarse Lapesa ${ }^{27}$ por la génesis de la interpolación del sujeto en las interrogativas indirectas canarias, caribeñas e italianas dialectales, a causa de encontrarse sólo muy tardiamente documentada, observa que la misma disposición "en las interrogativas indirectas del español y del italiano es simple pervivencia del uso latino correspondiente". Juzga, en cambio, "temerario afirmar lo mismo respecto a las interrogativas directas". Pero, sin "rechazar de antemano su continuidad con el latín", estima que "la interpolación del sujeto en ellas pudo haber subsistido en estado latente siglos y siglos", abierta a la posibilidad de que la disposición de las indirectas "haya contribuido a mantener la continuidad latente de la interpolación latina en las directas o, sin tal continuidad, se haya contagiado a ellas".

Para el caso presente - participio con complemento directo-, a diferencia del recién comentado, el recurso a la inducción sintáctica no se presenta necesario, puesto que la continuidad, aunque débil en los momentos iniciales, se mantuvo. Pero no encuentro ninguna dificultad, antes al contrario, para admitirlo, según he anticipado, en cuanto factor coadyuvante, cuya identificación paso a exponer inmediatamente.

11. Como estudié en otra ocasión ${ }^{28}$, desde época primitiva el castellano conoce con amplitud la enclisis pronominal en el participio de los tiempos

27 R. Lapesa, "La interpolación del sujeto en las oraciones interrogativas", Actas del II Congreso Internacional de Historia de la Lengua Española, Madrid, 1993, páginas 546-53; las citas, en las págs. 552-3.

a F. González Ollé, "Enclisis pronominal en el participio de las perífrasis verbales", RFE, 1983, LXIII, págs. 1-32. Tanto este estudio como el citado en la nota 1 del presente muestran la inexactitud de asegurar que "los participios [...] no admiten nunca la adjunción de un clítico", de modo que serían agramaticales tanto *He admirádolo mucho como *Una vez admirádolo, abandonamos la sala (O. Fernández Soriano, "Los 
compuestos, especialmente cuando llevaba un auxiliar común con otro participio o con más de uno: Aver tanto tiempo servídola (J. del Encina, Fileno).-Los habian despojado y dejádoles (G. Fernández de Oviedo, Historia). Dentro de esta organización sintáctica, cabe señalar algunos casos de particular interés para su aplicación actual. Son aquéllos, diversos, cuya estructura se presta a que el participio con pronombre enclítico se interprete como independiente del auxiliar. De la nómina inserta en mi estudio recién citado, destaco varios en que, por diferentes circunstancias sintácticas, se manifiesta esa proclividad a la aparente autonomía. Señalo algunas muestras características:

1) La larga separación lineal respecto del verbo auxiliar: No he quitado los artículos, como le parece a $V . m$. y esos señores, sino excusádolos donde no son necesarios (L. de Góngora, Carta).-Por cuyo amor habia hecho enormes sacrificios, perdido a mi madre idolatrada, experimentado la más viva ingratitud de un ente a quien favorecí con exceso $y$ enemistádome con mi única hermana (A. Alcalá Galiano, Memorias).--iCon qué gusto hubiera modelado él la estatua de don Juan, del "matador", como le llama con ingenuidad insuperable, $y$ puéstola entre las víctimas del héroe! (A. Machado, Mairena).

En la frase, sin ninguna relación con las anteriores por su carencia de la anáfora pronominal examinada: Habia bajado al mar -de ahi venia el bronceado- y recorrido toda la costa malagueña (A. Pombo, El metro de platino iridiado), obsérvese cómo la circunstancia expuesta (separación lineal), muy potenciada por la interposición ante el segundo participio de una cláusula parentética (con su correspondiente delimitación fónica, con su tono más bajo y con su tonema de cadencia) obscurece la coordinación. De este modo facilita llegar al resultado analítico -obviamente erróneo- de

pronombres átonos en la teoría gramatical. Repaso y balance", en Id., Los pronombres átonos, Madrid, 1993, págs. 13-62; la cita, pág. 39). Se pluede, eso sí, aceptar su decadencia y aun augurar su desaparición, siempre que no se olvide su presencia, a efectos cronológicos, en poetas como Machado y Vallejo, cuentistas como Aldecoa, críticos literarios como Menéndez Pelayo y Avalle-Arce, políticos como Azaña, etc.

El rotundo rechazo anterior parece, sin embargo, un descuido momentáneo, puesto que en la nota 47 de su trabajo, indica Fernández Soriano: "Véase el trabajo de González Ollé (1983) para un análisis de estas construcciones de participio con clítico en espaffol antiguo." Esta referencia viene provocada al discutir una explicación ajena: "Mendikoetxea (en este volumen [A. Mendikoetxea, "Los clíticos como categorías subléxicas de concordancia", págs. 205-30]) deriva esta propiedad del hecho de que los participios en estas construcciones son pasivos en espafiol (y, por tanto, no admiten cliticos en acusativo, como las pasivas regulares), mientras que en italiano son activos. Queda pendiente, no obstante, la cuestión de por qué tampoco coaparecen con otro tipo de clíticos" (no acabo de entender con seguridad si en esta última frase se reitera el rechazo inicial). 
que un participio independiente, recorrido, lleva un complemento directo, costa.

2) Esa separación se realza además cualitativamente en los diálogos, si el participio con enclisis tiene su verbo auxiliar en el parlamento de otro interlocutor: Pinciano dixo entonces: [...] Holgara saber si algún varón graue antiguo auia emprimado vuestra doctrina.-Hugo dixo: l'Qué emprimado! i $Y$ aun bosquexado $y$ aun retocádola a mi parecer! (A. López Pinciano, Filosofía antigua poética).

3) La diferencia de sujeto gramatical de los participios, con las consecuentes anomalías de concordancia: Lo que el Señor me ha enseñado por espiriencia, y después tratádolo yo con grandes letrados (Santa Teresa, Vida).-Hase alborotado el lugar, como si yo fuera cosa de consideración en él, $y$ visitádome señores (Lope de Vega, Carta).

4) La combinación de los dos primeros factores aqui presentados: Aviendo tratado, conversado y comunicado con él no le avéis conocido.¿Qué dizes, hombre? iNosotros vístole, hablado, y comunicado con él? (B. Gracián, Criticón).

5) El funcionamiento ambivalente de haber, pleno y auxiliar: No podía auer degeneración ni usádose tantos vocablos (G. López Madera, Discursos).

Testimonios como los recién transcritos - pero también otros muchos sin sus notas peculiares - han podido contribuir a mantener $\mathrm{y}$ a fomentar el uso del participio independiente con complemento directo pronominal enclítico e, indirectamente, a través o a imitación de éste, con complemento directo nominal.

Esta suposición se ve reforzada por la correspondencia cronológica de las dos especies de participio con complemento. La proliferación de participio independiente con pronombre enclítico conoce su auge en los siglos xvI ${ }^{29}$ y xVII, precisamente durante la época que brinda más extensa documentación de participio con enclisis en los tiempos compuestos. Cuando, después, esta última modalidad de enclisis decae, aquélla se reduce asimismo, hasta el extremo de que no he conseguido documentarla en el siglo xvirI, si bien debió de sobrevivir en él, pues se manifiesta, aunque muy raramente, en los siglos posteriores.

Así y todo, debe quedar muy claro que la acción de los participios con pronombre enclítico, integrados en los tiempos compuestos, sobre la construcción con complemento directo de los participios independientes, hubo de ser, a lo sumo, pese a estar aquélla mucho más difundida, concausa tardia y

20 También era característica de este siglo en italiano, al parecer de Migliorini (8 1). Pero, salvo algún posible caso aislado, imputable quizá, en principio, a la vinculación personal de su autor con Italia, no existen motivos para suponer una influencia generalizada de este origen sobre el uso sintáctico espafiol. 
no causa. Se evidencia este comportamiento por el dato de que en los últimos la incidencia del complemento directo nominal supera abrumadoramente a la del complemento directo pronominal ( 50 casos frente a 11 , como antes informé).

12. Tras esta exposición detallada de la posible influencia analogizante, reitero mi postura sobre la cuestión investigada en el presente estudio: el participio pasado con complemento directo es continuación de idéntica construcción latina. A su sostenimiento han podido contribuir otros factores secundarios; entre ellos ( $§ 9)$, de modo especial, la analogía recién analizada. 